\title{
Microvascular free tissue reconstruction following extirpation of head and neck tumour: experience towards an optimal outcome
}

\author{
L. K. Lam, F.R.A.C.S., William I. Wei, M.S., F.R.C.S., Vana S. H. Chan, F.R.C.S.(Ed.), Raymond \\ W. M. NG, F.R.C.S.(ED.), W. K. Ho, F.R.C.S.(Ed.)
}

\begin{abstract}
Familiarity with four types of free tissues transfers allows appropriate reconstruction of most defects in the head and neck region functionally and aesthetically. These include jejunal graft, radial forearm, rectus abdominus myocutaneous and fibula osteocutaneous flaps. Free colonic and gastric patches were used occasionally.

We report our experience of 215 free tissue transfers for reconstruction of defects in the head and neck region after tumour extirpation.

The overall success rate was 94 per cent. The commonest cause of failure was related to arterial inflow (70 per cent). Three patients died in hospital, but their mortality was not related to the tissue transfers. Complications due to free tissue transfer at both the donor and recipient sites were few and manageable.

The co-operation between the two surgical teams, together with the timely application of suitable salvage procedures, contribute to an optimal outcome.
\end{abstract}

Key words: Head and Neck Neoplasms; Surgical Flaps; Outcome Assessment (Health Care)

\section{Introduction}

Myocutaneous flaps, first introduced in the 1980s have become the most frequently employed method for reconstruction of defects in the head and neck region after tumour extirpation. Raising a myocutaneous flap is technically easy and its reliable blood supply is another advantage. However, it does not provide an optimal reconstruction because of the muscle bulk and thick subcutaneous tissue. Despite various modifications reported, the arc of rotation of the myocutaneous flap is limited by the location and length of the pedicle. ${ }^{1-3}$

Microvascular free tissue transfer for reconstruction of various defects in the head and neck region following tumour resection is considered to give better results, both functionally and aesthetically. ${ }^{4,5}$ The most appropriate tissue or organ can be selected and moved to the defect for reconstruction. ${ }^{6}$ Both resection of tumour and harvesting of the free tissue can usually be performed simultaneously, thus reducing the operating time and duration of general anaesthesia. To perform both the resection and reconstruction successfully, a number of criteria are essential. Surgical expertise is firstly required at the resection site, to prepare the recipient vessels, secondly at the donor site, to harvest the appropriate free tissue, thirdly to carry out the microvascular anastomosis and finally to inset the tranposed tissue.

In some centres, the resection and reconstruction are performed by two separate teams and special cooperation between them is necesssary for a favourable outcome. These include the choice of the free tissue to be employed, the timing of resection and free tissue harvesting, the preparation of recipient vessels and microvascular anastomosis. More importantly, the teams must co-operate to decide on appropriate salvage procedures when the initial free flap fails. The present study reports microvascular free tissue transfer experience gained in our centre to show that through preoperative planning such as choice of the tissue, preparation of recipient vessels, good results could be achieved using microvascular free tissue transfer for reconstruction of a variety of defects following tumour extirpation in the head and neck region. In addition, we have achieved good co-ordination by establishing two surgical teams, either of which can perform resection and reconstruction procedures.

\section{Patients and methods}

The head and neck division of the department of surgery, University of Hong Kong Medical Centre at 


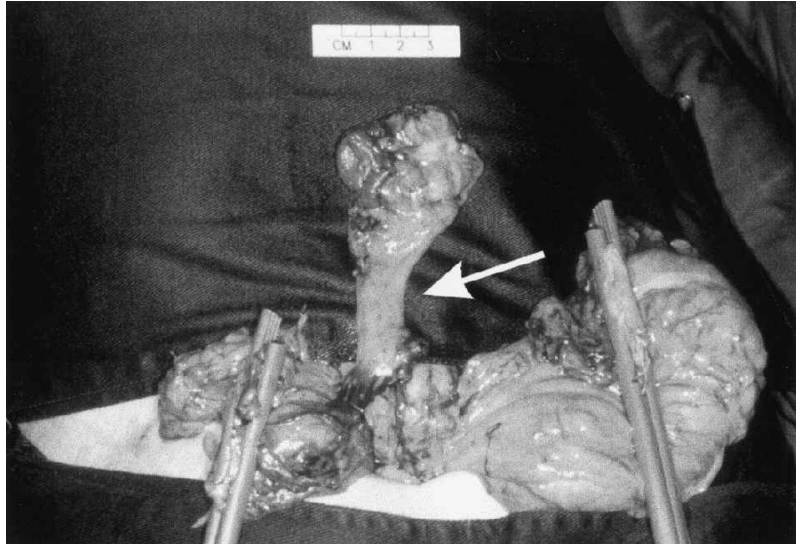

(a)

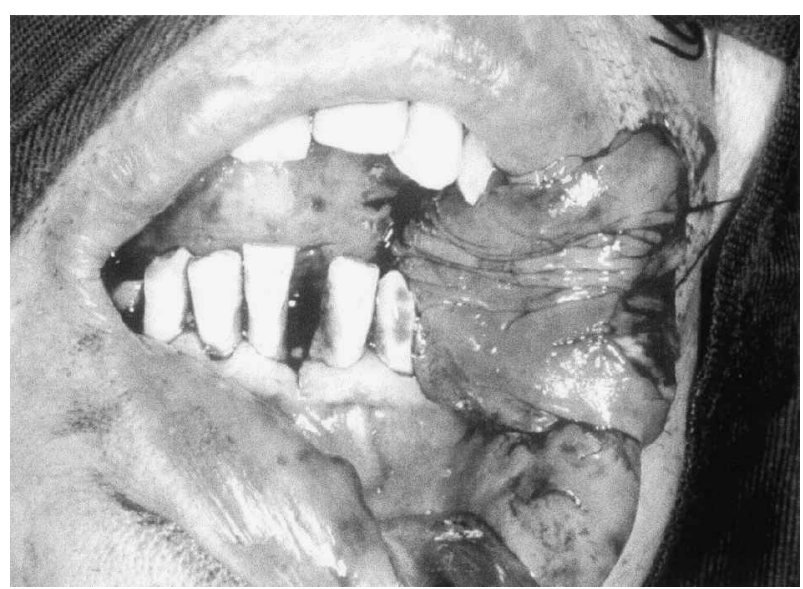

(b)

FIG. 1

(a) Segment of transverse colon prepared for transfer, blood supply is from middle colic vessels (arrow). (b) Colon opened to provide mucosal cover for buccal mucosa.

Queen Mary Hospital, Hong Kong SAR, China, is comprised of otorhinolaryngologists, head and neck surgeons and plastic and reconstructive surgeons. Members of the division are trained both in extirpation of malignancy in the head and neck region and in the harvesting of commonly employed free tissues used for reconstruction. All members in the division have acquired the technique of microvascular anastomosis under magnification through regular practice on animals. From 1983 to 2000, we have carried out 215 microvascular free tissue transfers for reconstruction of defects created after extirpation of tumours in the head and neck region. Among these patients, 149 were male and 66 were female. Their ages ranged from 12 to 86 years, median 58.7 years.

All free tissue transfers were employed for the reconstruction of defects following extirpation of tumour in the head and neck region. Reconstruction was performed essentially for four types of defect. Following resection of intraoral tumour or dermatological pathology, the subsequent mucosal or cutaneous defect required coverage. When segmental mandibulectomy was performed for tumour arising from the lower alveolus, the bony defect and the intraoral mucosal deficiency needs to be reconstructed simultaneously. After circumferential pharyngectomy, the gap between the oropharynx and oesophagus must be filled to reconstitute the continuity of the alimentary tract. Finally, after removal of a bulky tumour, the tissue defect, with, or without, the overlying skin has to be reconstructed to achieve a functional or aesthetic outcome.

Free tissue used for the first type of defect include the radial forearm flap, ulnar forearm flap, lateral arm flap and groin flap. Patches of colonic mucosa (Figure 1) or gastric mucosa (Figure 2) have also been used for reconstruction of intraoral mucosal defects. For the reconstruction of mandibular defects, the fibula and overlying skin island constituting an osteocutaneous flap were frequently used. In the early years, the radial forearm flap carrying with it a narrow block of radius bone was used. To repair circumferential pharyngeal defects, free jejunal grafts were most frequently employed and occasionally, a tubed radial forearm flap was used. Free rectus abdominis muscle or myocutaneous flap

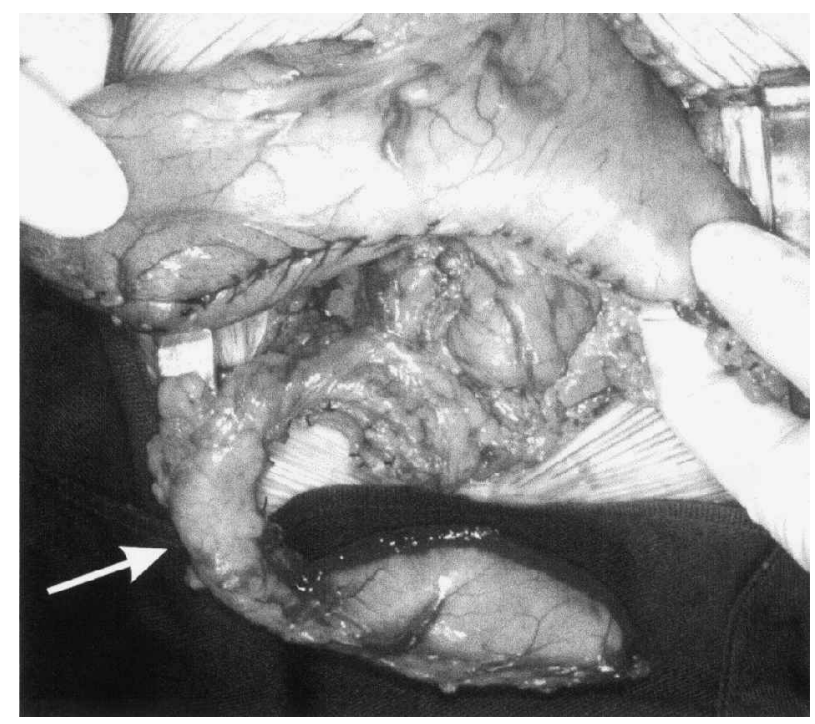

(a)

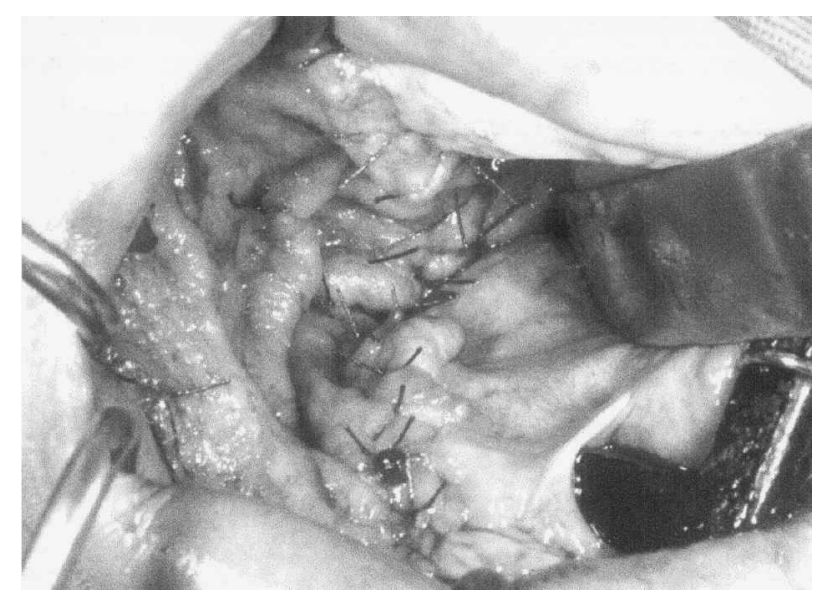

(b)

FIG. 2

(a) Part of stomach with blood supply from right gastroepiploeic vessels (arrow) prepared for transfer. (b) Gastric mucosal patch insetted for buccal mucosa reconstruction. 
TABLE I

INDICATIONS OF FREE TISSUE TRANSFER FOR BENIGN PATHOLOGIES IN THE HEAD AND NECK REGION

$\mathrm{n}=18$

Type of benign condition

No.

Cutaneous defects following infection or trauma

Osteoradionecrosis

Neopharyngeal stricture

Cutaneous lesion

Romberg's disease

Arteriovenous malformation

and free latissimus dorsi myocutaneous flap have been employed to fill bulky defects. ${ }^{7-9}$ The latter has also been used to cover a large cutaneous defect. ${ }^{10}$

\section{Techniques}

The recipient artery included the superior thyroid artery, facial artery at the level of the posterior border of the diagastric muscle or the lower border of the mandible and the superficial temporal artery. Branches of the posterior facial vein were the most frequently used recipient vein. Other branches of the internal jugular vein accompanying the recipient artery and even the external jugular vein have been used. Microvascular anastomosis was performed with interrupted 9/0 Ethilon sutures under an operating microscope. End to end anastomosis was preferred.

Harvesting of free tissue was performed immediately by the second surgical team when the dimension of the defect created following resection was known. Identification and preparation of recipient vessels were performed simultaneously with the harvesting of donor tissue. When cutaneous free tissue was harvested from a limb, a tourniquet was routinely used. The free tissue, when properly prepared, was left to perfuse and it was transferred only when the recipient site was ready. This reduced the ischaemic insult to the free tissue.

When the transferred tissue was moved to the recipient site, the flap was first insetted to gain stability before the microvascular anastomosis. For free jejunal graft, the jejuno-oesophageal anastomosis was performed first.

Microvascular anastomosis was then performed and when the bowel regained its blood supply, jejuno-oropharyngeal anastomosis was performed. The microvascular anastomosis was performed under the operating microscope using interrupted 9/0 Ethilon sutures. The free tissue transferred was not perfused, the vessel lumen distal to the clamps was irrigated with heparin saline solution at a concentration of 10 units $/ \mathrm{mL}$.

For donor site defect, primary closure was performed whenever possible, otherwise, split thickness skin graft was used. When a segment of the bowel was used, then the continuity of the alimentary tract was reconstituted with end to end anastomosis.

The transferred free tissue, in particular those with a cutaneous element, was monitored by clinical observation only. The free jejunal graft mucosa was
TABLE II

LOCATIONS OF MALIGNANT LESIONS WHICH AFTER RESECTION, NEED FREE TISSUE TRANSFER FOR RECONSTRUCTION

$\begin{array}{lc}\text { Location of primary tumour } & \mathrm{n}=197 \\ \text { No. }\end{array}$

inspected with a flexible endoscope inserted through the nasal cavity daily for a few days after operation. No other monitoring instrument was employed.

\section{Methods of salvage}

The pectoralis major myocutaneous flap was the flap of choice when the free tissue used for reconstruction of a cutaneous or mucosal defect failed. When the fibula osteocutaneous flap failed, the pectoralis major myocutaneous flap together with a reconstruction plate was the favoured salvage option. When a free jejunal graft failed, the defect was reconstructed in stages. The posterior pharyngeal wall was first reconstructed with a deltopectoral flap. Then at a second stage, the pectoralis major myocutaneous flap completed the reconstruction as the anterior wall.

\section{Results}

Among the 215 free tissue transfers, 18 were performed for benign pathologies such as stricture of the neopharynx, and osteoradionecrosis. The indications are listed in Table I. The other 197 were performed following extirpation of malignant lesions in the head and neck region. The locations of the primary tumour are shown in Table II. When the primary tumour was in the oral cavity, they were mostly stage $T_{1}$ or $T_{2}$ lesions while with primary hypopharyngeal carcinoma they were all $\mathrm{T}_{3}$ and $\mathrm{T}_{4}$

\section{TABLE III}

NUMBER OF EACH TYPE OF FREE TISSUE EMPLOYED FOR RECONSTRUCTION (AND FAILURE)

\begin{tabular}{lcc} 
Type of free tissue & $\begin{array}{c}\text { Number } \\
\text { performed }\end{array}$ & $\begin{array}{c}\text { Number } \\
\text { failed }\end{array}$ \\
\hline Radial forearm flap & 69 & 2 \\
Radial forearm flap + radius & & \\
$\quad$ bone & 8 & 3 (5 patients loss \\
Fibular osteocutaneous & & of skin island only) \\
Jejunum & 44 & 3 \\
Rectus abdominis & & \\
$\quad$ myocutaneous flap & 15 & 1 \\
Latissimus dorsi myocutaneous & & 3 \\
$\quad$ flap & 11 & 1 \\
Lateral arm flap & 5 & 0 \\
Ulnar free cutaneous flap & 3 & 0 \\
Groin flap & 1 & 0 \\
Colon & 4 & 0 \\
Gastric patch & 1 & 13 \\
Total & 215 &
\end{tabular}


TABLE IV

NUMBER OF FREE TISSUE TRANSFERS PERFORMED OVER THE YEARS, SUCCESSES AND FAILURES

\begin{tabular}{lcc} 
Year & $\begin{array}{c}\text { Total number } \\
\text { performed }\end{array}$ & Number failed \\
\hline $1983-85$ & 3 & 0 \\
$1986-88$ & 12 & 1 \\
$1989-91$ & 8 & 3 \\
$1992-94$ & 75 & 5 \\
$1995-97$ & 52 & 3 \\
$1998-2000$ & 53 & 1 \\
Total & 215 & 13
\end{tabular}

tumours. The types of free tissue transfer performed and the failure rate for each type are listed in Table III. The number of free tissue transfer carried out every year in our centre is listed in Table IV. Three patients died in hospital following the operation. None of the deaths were directly related to the free tissue transfer. For the first patient, a latissimus dorsi myocutaneous flap was used to cover a dural defect after craniofacial resection. Despite full viability of the flap, the patient developed meningitis and died. The second patient also had a skull base defect successfully repaired but subsequently succumbed to a ruptured urinary bladder related to a catheter problem.

The third patient underwent a free jejunal graft for reconstruction of a circumferential pharyngeal defect. The operation was uneventful but the patient developed a massive myocardial infarction and died in the recovery room. All other patients survived the operation and were discharged from the hospital.

Optimal outcome means expedious recovery after adequate tumour extirpation and in addition, long periods of survival with good aesthetic and functional recovery. A quality of life assessment was not performed in view of the wide range of primary pathologies. The assessment of surgical and functional outcome was mainly based on subjective clinical impression. When the free tissue transfer was successful, the recovery was faster than conventional reconstruction, as minor complications are infrequently seen with free tissue transfer. Most patients were discharged from the hospital within seven to 10 days after surgery. The aesthetic results were also superior to conventional reconstruction methods. This is because the most appropriate tissue or composite tissue were used for reconstruction to match tissue bulk and texture.

\section{Failures}

Of the 13 unsuccessful free tissue transfers, three occurred on the operating table immediately following the microvascular anastomosis. In two of these three patients, the weight of the latissimus dorsi muscle sank into the hollow cavity, pulling on the arterial anastomosis leading to narrowing and thrombosis. In the remaining patient, the recipient superior thyroid artery was narrowed by atheroma and this was not detected before the microvascular anastomosis. After the clamps were released, the arterial inflow was noted to be inadequate. When the problem was identified and the jejunal artery joined

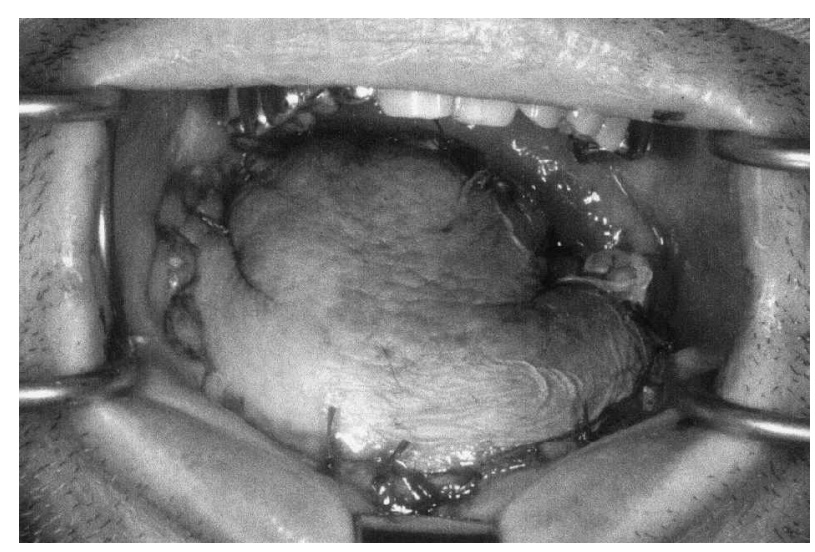

(a)

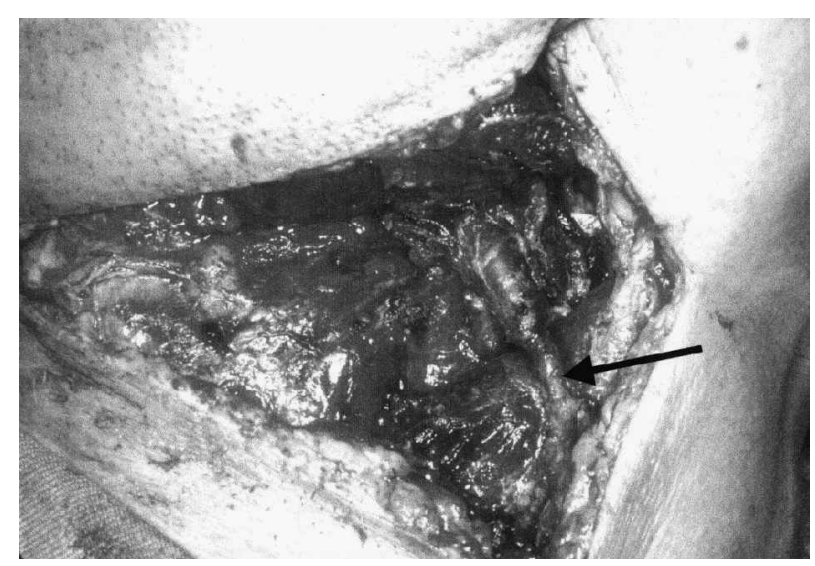

(b)

FIG. 3

(a) Skin island of a fibula osteocutaneous flap showing venous congestion. (b) Venous thrombosis related to the compression of the vascular pedicle by a neck drain (arrow).

to another branch of the external carotid artery, the ischaemic time was too long for the free graft to survive.

The other 10 failures were detected in the postoperative period. For five patients, kinking of the vascular pedicle was determined at the time of reexploration and this was identified as the cause of free tissue failure. In another two patients, the drains inserted into the neck had compressed the vascular pedicle and this led to flap failure (Figure 3). One patient vomited on the third day following a free jejunal graft. The patient aspirated the vomitus through the terminal tracheostomy and subsequently developed aspiration pneumonia and septicaemic shock. Although the patient was resuscitated, the low and fluctuating blood pressure during the septic phase led to thrombosis of the arterial anastomosis and consequent loss of the jejunal graft. One patient developed venous thrombosis at one week after the operation while for the remaining patients, no exact cause was identified for the failure of the free tissue transfer (Table V).

The skin islands of five fibula osteocutaneous flaps died in the post-operative period despite patent vascular pedicles. These were related to the kinking of the small septo-cutaneous perforator supplying the cutaneous element. 
TABLE V

CAUSES OF FAILURE OF FREE TRANSFER $(\mathrm{N}=13)$

Number

Causes of early failure

Dragging of pedicle

Atheroma in artery

Causes of delayed failure

Kinking of pedicle

Drain compressing on vein

Hypotension, arterial thrombosis

Venous thrombosis

Unknown

\section{Complications}

Microvascular free tissue transfer has an adequate blood supply. Therefore, associated complications, both at the recipient and donor sites were few.

(1) Recipient site problem. Partial necrosis of transferred free tissue was uncommon. Therefore, when free tissue was employed for intra-oral lining, dehiscence of repair followed by leakages was rare. One patient, after free jejunal graft, developed a mild stenosis at the jejuno-oesophageal anastomosis at six months after the operation and this was managed successfully with dilatation.

(2) Donor site problem. Of the eight patients for whom a partial segment of the radius bone was transferred with the radial forearm flap for mandibular reconstruction, three developed a green stick fracture at the radius donor site three months after the operation. This occurred despite the application of a plaster of Paris cast for six weeks for all the eight patients after the operation.

Part of the split thickness skin graft employed to cover the donor site defect failed to survive in four patients. This took place over the tendons. In three patients, it was over the peroneus longus tendon where a fibula osteocutaneous flap was used. In one patient, where a radial forearm flap was used, the split thickness skin graft failed over the palmaris longus tendon region. With conservation treatment all these wounds eventually healed although in one patient, this took three months. Two patients in the free jejunal group developed intussusception during convalescence and both recovered well after resection of the affected intestinal segment.

\section{Discussion}

The reconstruction of defects in the head and neck region has been a challenging problem for head and neck surgeons. Besides filling a gap, there are both functional as well as aesthetic considerations. The need for adequate resection of a malignant tumour that is crucial to the final outcome may create defects that are difficult to reconstruct with conventional methods. The loss of tissue may be extensive or the tissue destruction may involve composite elements. Furthermore, tissue around the defect might have been previously irradiated and saliva contamination might affect wound healing. The application of microvascular free tissue transfer allows the selection of the most appropriate tissue for reconstruction. As free tissue brings a new blood supply, wound healing is usually not a problem. Despite all the benefits of microvascular free tissue transfer, these procedures are not routinely performed in head and neck centres. This might be due to the difficulty in coordinating the resection and reconstruction teams to work effectively, so that the whole operation can be performed smoothly and efficiently.

In our centre, we address this problem by establishing two teams. Both teams are involved in the resection of the primary tumour and application of free tissue transfer for reconstruction. The preparation of recipient vessels at the primary site could be started at the time of tumour resection. On the one hand, important recipient vessels are not sacrificed inadvertently while on the other hand, adequate tumour resection is not compromised. During the harvesting of free tissue, the vascular pedicles were also prepared simultaneously for subsequent microvascular anastomosis. With two competent teams, the whole operation can be carried out effectively and smoothly. This greatly shortens the operating time and the duration of general anaesthesia. In the early years, two to three microvascular free tissue transfers were carried out per year and in recent years, this has reached a plateau. Currently approximately 20 microvascular free tissue transfers are carried out every year.

Previously about one patient out of 50 patients who required reconstruction was treated using free tissue transfer. The total number of patients who required reconstruction after tumour extirpation has been approximately 100 every year and free tissue transfer has been used for 20 per cent of them. Microvascular free tissue transfer is used invariably for reconstruction of defects in the upper face, scalp, skull vault and skull base. The number of pedicle flaps applicable in these regions were few. For many pathologies in the head and neck region, microvascular free tissue transfer is the primary modality of reconstruction. Pedicle flap or tissue is used to reconstruct partial pharyngectomy defects and defects after resection of oral cancers with extensive neck disease. When tumour extirpation warranted the removal of whole oesophagus for lower hypopharyngeal carcinoma, then the stomach is brought up for reconstruction.

Microvascular free tissue is also not used for very old patients and patients with compromised cardiopulmonary status. When pre-operative doppler revealed inadequate arterial blood flow or when neck tissue were affected by heavy radiation, then pedicle flaps were not used.

The overall success rate of free tissue transfer in the present study was 94 per cent, and is comparable to reports from other centres. ${ }^{11,12}$ This was achieved with the co-ordination of the two teams in tumour resection, harvesting of free tissue, performing the microsurgical vascular anastomosis and insetting of transferred tissue. For reconstruction of most defects following extirpation of lesions in the head and neck region, one needs to be acquainted with only a few commonly employed free tissue transfers. For cutaneous or mucosal lining, the radial forearm flap 


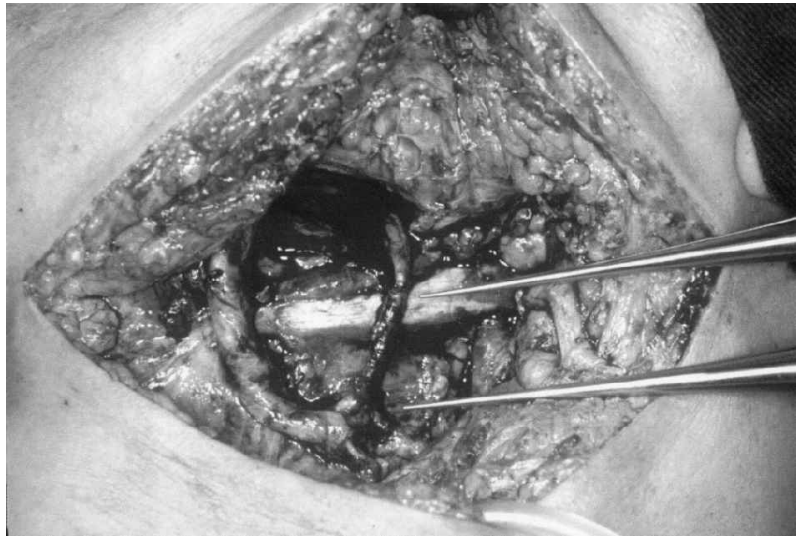

FIG. 4

Radial forearm flap used for reconstruction of intraoral defect. The long pedicle delivered to the neck forms a smooth gentle curve, avoids kinking (pointed by tip of forceps).

is appropriate. ${ }^{12-14}$ Where there is tissue loss then the myocutaneous free flaps with, or without, the cutaneous element are useful. The fibula osteocutaneous flap is suitable for reconstruction of the segmental mandibular defect associated with an intra-oral defect. ${ }^{15,16}$ For central arch mandibular defects, osteotomy of the fibula can be performed and fixation with mini-plates used to reconstruct the shape of the central mandible. This can be done before releasing the tourniquet to reduce the ischaemic time. The free jejunal graft is ideal for the reconstruction of a circumferential hypophyarngeal defect. ${ }^{17-20}$ The surgical anatomy of these tissues is not complicated and with practice, it is not difficult to raise these tissues for reconstruction of the appropriate defect. Familiarity with these common tissues is adequate for reconstruction of most defects in the head and neck region. Under special circumstances, such as for buccal mucosal defects, colon or gastric patches have been used for reconstruction. These tissues can be stretched allowing for a wider mouth opening.

The most frequent cause of free flap failure was related to the condition of the vascular pedicle. Kinking of the vascular pedicle can be avoided with careful planning during the preparation of the recipient vessel. As long a length as possible of donor vessels are harvested. This allows for a gentle curving of the pedicle and prevents any acute bending (Figure 4). During the delivery of the vascular pedicle through the floor of the mouth or subcutaneous tunnel, it may twist within the tunnel leading to flap failure. The vascular pedicle is routinely placed through a large bore chest drain after harvesting the free tissue. The whole tube containing the vascular pedicle and the vascular clamps were then inserted through the tissue tunnel to be delivered towards the recipient vessels. This avoids twisting of the vascular pedicle (Figure 5).

The patient's head is usually turned laterally to allow adequate exposure for microvascular anastomosis. The position of the vascular pedicle may move when the head is returned to the neutral position and kinking of the vascular pedicle may result. It is mandatory to check the final status of the vascular pedicle with the patient's head placed in the neutral position. Free tissue is usually partially insetted before the microvascular anastomosis to prevent dragging of the pedicle. Additional stitches were used to eliminate the weight of the tissue, especially when muscle bulk was transferred as free tissue. For the same reason, in free jejunal graft, the lower jejuno-oesophageal anastomosis was performed before the microvascular anastomosis. The upper jejuno-oropharyngeal anastomosis usually takes longer to complete and this may increase the overall ischaemic time. Therefore, it was performed after the microvascular anastomosis when the bowel has been revascularized.

The free tissue after elevation should be left in situ to be perfused. Besides reducing metabolites that had accumulated when the flap was raised, any bleeding points detected with reperfusion of the tissue can be stopped to prevent subsequent bleeding and formation of haematoma after transfer to the recipient site.

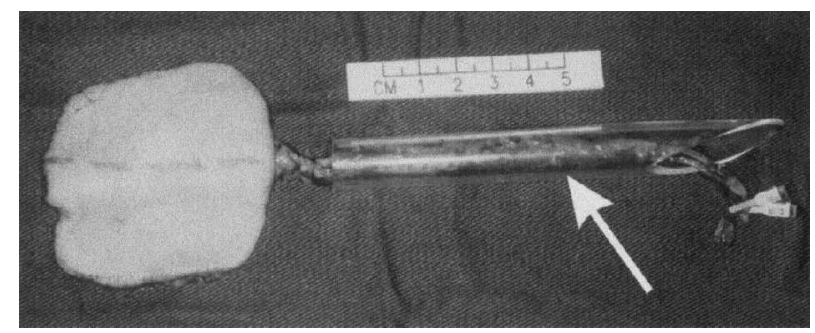

(a)

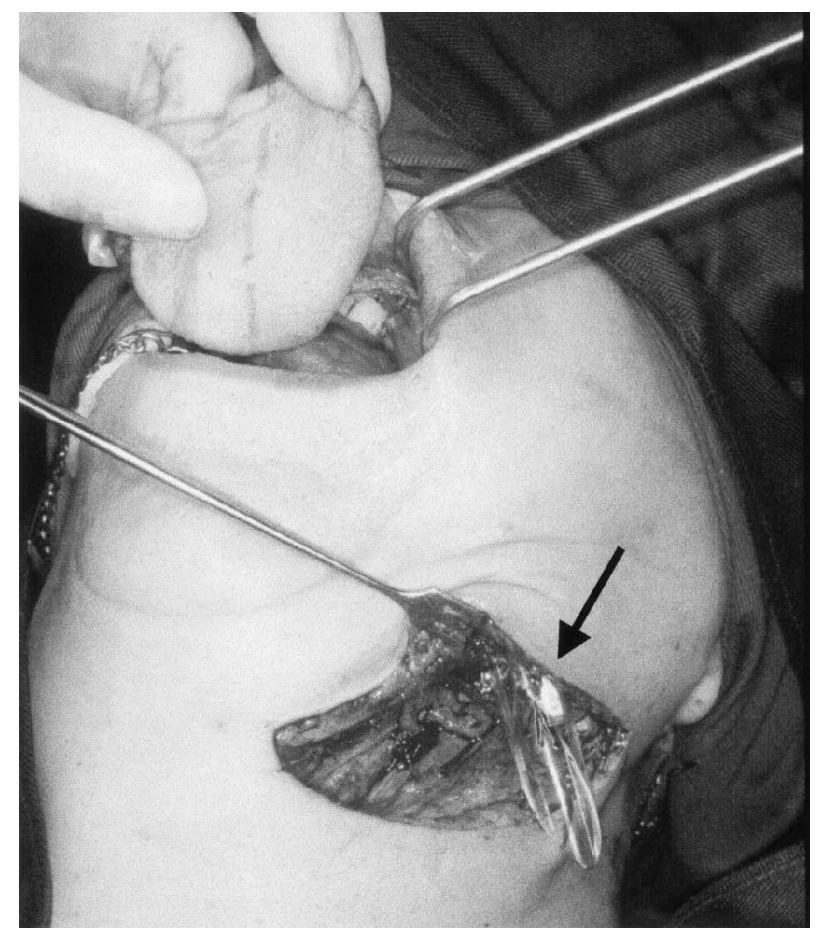

(b)

FIG. 5

(a) The vascular pedicle of radial forearm flap is placed within a wide-bore plastic tube (arrow). (b) The whole tube (arrow) is inserted through the tissue tunnel to avoid kinking of the vascular pedicle. 
In view of the abundant blood supply of free tissue, complications at the recipient sites were uncommon. The transposed jejunum was also able to tolerate post-operative radiotherapy. ${ }^{21}$ Stenosis at the jejuno-oesophageal junction in the patient who had free jejunal transfer was probably related to the technique of bowel anastomosis. The mild stenosis subsequently responded to dilatation. The loss of the skin island in the fibula osteocutaneous flap was related to the kinking of the tiny septocutaneous perforators. Adequate planning of the skin island and positioning of the flap will reduce this complication. A more troublesome complication was the failure of survival of the split thickness skin graft over the tendon at the donor site. During the harvesting of free tissue, some paratenon should be left on the tendon at the donor site. The partial thickness skin graft should be immobilized completely to improve the chance of survival. Besides tieover dressing, a plaster of Paris cast may sometimes be applied in addition for immobilization. ${ }^{22}$

The intussusception following jejunojejunal anastomosis was related to the technique of bowel anastomosis. This complication could be avoided if care is exercised at the intestinal anastomosis, especially by not taking up an excessive amount of bowel wall during the anastomosis.

With practice and experience, the success of free tissue transfer will further improve. There is, however, always the possibility that it may fail and, therefore, a salvage procedure should be available. The pectoralis major myocutaneous flap has been our backup flap for salvage of free tissue transfer failure. However, other myocutaneous flaps can also be used. ${ }^{23}$ In our centre, a second free tissue transfer has not been used as salvage. This is because when the first free tissue transfer fails, the region is usually contaminated and the local tissue is not in its best condition. Another consideration is that the best recipient vessels usually have already been used for microvascular anastomosis and alternative vessels may not be available.

For failed fibula osteocutaneous tissue transfer used in the reconstruction of segmental mandibular defects, pectoralis major myocutaneous flap can be used for reconstruction of the intraoral lining and metallic reconstruction plate employed for the segmental mandibular defect. Although the reconstruction plate may lead to other problems later such as extrusion and infection, it reconstructs the mandibular defect quickly and satisfactorily so that the patient can tolerate an oral diet well.

For failed free jejunal graft used in the reconstruction of a circumferential pharyngeal defect, a twostaged reconstruction was employed as salvage. Debridement and cleaning of the local region was first performed and then reconstruction of the posterior pharyngeal wall was carried out using a deltopectoral flap. These procedures exteriorize the oropharynx and the upper end of the oesophagus, thus eliminating the contamination of surrounding tissue with saliva. When the wound in the neck heals then second stage reconstruction can be carried out satisfactorily with the pectoralis myocutaneous flap. One-stage reconstruction at the time of taking down the non-viable jejunum may not be applicable in view of sepsis and condition of local tissue. All of our patients have been salvaged successfully with these measures - thus eliminating hospital mortality associated with free tissue transfer for head and neck reconstruction.

Through detailed pre-operative planning of surgical procedure, patient and tissue selection, the resection and reconstruction teams function as one unit. The good co-operation contributes towards the high success rate of free tissue transfer and this provides an optimal outcome for these patients.

\section{References}

1 Futran ND, Alsarraf R. Microvascular free-flap reconstruction in the head and neck. J Am Med Assoc 2000;284: 1761-3

2 Futran ND, Haller JR. Considerations for free-flap reconstruction of the hard palate. Arch Otolaryngol Head Neck Surg 1999;125:665-9

3 Wei WI, Lam KH, Wong J. The true pectoralis major myocutaneous island flap: an anatomical study. $\mathrm{Br} J$ Plast Surg 1984;37:568-73

4 Daniel RK, May JW, Jr. Free flaps: an overview. Clin Orthop 1978;133:122-31

5 Hayden RE. Microvascular free flaps for soft tissue defects. Otolaryngol Clin North Am 1991;24:1343-6

6 Yim KK, Wei FC. Free tissue transplantation in the 90's. Int Angiol 1995;14:327-31

7 Markowitz BL, Satterberg T, Calcaterra T, Orringer J, Cohen S, Burstein F, et al. The deep inferior epigastric rectus abdominis muscle and myocutaneous free tissue transfer: further applications for head and neck reconstruction. Ann Plast Surg 1991;27:577-82

8 Meland NB, Fisher J, Irons GB, Wood MB, Cooney WP. Experience with 80 rectus abdominis free-tissue transfers. Plast Reconstr Surg 1989;83:481-7

9 Jones NF, Sekhar LN, Schramm VL. Free rectus abdominis muscle flap reconstruction of the middle and posterior cranial base. Plast Reconstr Surg 1986;78:471-7

10 Sabatier RE, Bakamjian IY. Transaxillary latissmus dorsi flap reconstruction in head and neck cancer, limitations and refinements in 56 cases. Am J Surg 1985;150:427-34

11 Tsuji H, Minami T, Yamashita T, Kumazawa T. Head and neck reconstruction with microvascular tissue transfer and its surgical indications: our experience. Acta Otolaryngol (Stockh) 1993;(Suppl. 500):131-4

12 Evans GRD, Schusterman MA, Kroll SS, Miller MJ, Reece GP, Robb GL, et al. The radial forearm free flap for head and neck reconstruction: a review. Am J Surg 1994;168:446-50

13 Schusterman MA, Kroll SS, Weber RS, Byers RM, Guillamondegui O, Goepfert $\mathrm{H}$. Intraoral soft tissue reconstruction after cancer ablation: a comparison of the pectoralis major flap and the free radial forearm flap. Am J Surg 1991;162:397-9

14 Urken MI, Weinberg H, Vickery C, Biller HF. The neurofasciocutaneous radial forearm flap in head and neck reconstruction: a preliminary report. Laryngoscope 1990;100:161-73

15 Flemming AFS, Brough MD, Evans ND, Grant HR, Harris M, James DR, et al. Mandibular reconstruction using vascularized fibula. Br J Plast Surg 1990;43:403-9

16 Wei FC, Seah CS, Tsai YC, Liu SJ, Tsai MS. Fibula osteoseptocutaneous flap for reconstruction of composite mandibular defects. Plast Reconstr Surg 1994;93:294-304

17 Jones AS, Roland NJ, Husband D, Hamilton JW, Gati I. Free revascularized jejunal loop repair following total pharyngolaryngectomy for carcinoma of the hypopharynx: report of 90 patients. Br J Surg 1996;83:1279-83 
18 Yamamoto Y, Nohira K, Shintomi Y, Yoshida T, Minakawa $\mathrm{H}$, Okushiba S, et al. Mesenteric flap in free jejunal transfers: a versatile technique for head and neck reconstruction. Head Neck 1995;17:213-8

19 Schusterman MA, Shestak K, deVries EJ, Swartz W, Jones $\mathrm{N}$, Johnson $\mathrm{J}$, et al. Reconstruction of the cervical esophagus: free jejunal transfer versus gastric pull-up. Plast Reconstr Surg 1990;85:16-21

20 Reece GP, Schusterman MA, Miller MJ, Kroll SS, Robb GL, Baldwin BJ, et al. Morbidity and functional outcome of free jejunal transfer reconstruction for circumferential defects of the pharynx and cervical oseophagus. Plast Reconstr Surg 1995;96:1307-16

21 Wei WI, Lam LK, Yuen PW, Kwong D, Chan KW. Mucosal changes of the free jejunal graft in response to radiotherapy. Am J Surg 1998;175:44-6

22 Swanson E, Boyd JB, Manktelow RT. The radial forearm flap: reconstructive applications and donor-site defects in 35 consecutive patients. Plast Reconstr Surg 1990;85: 258-66
23 Coleman JJ, Tan KC, Searles JM, Hester TR, Nahai F. Jejunal free autograft: analysis of complications and their resolution. Plast Reconstr Surg 1989;84:589-95

Address for correspondence:

Professor William I. Wei,

Department of Surgery,

University of Hong Kong Medical Centre,

Queen Mary Hospital,

Hong Kong.

Fax: (852) 28184407

Professor W. Wei takes responsibility for the integrity of the content of the paper.

Competing interests: None declared 